\title{
Gastric Antral Vascular Ectasia
}

National Cancer Institute

\section{Source}

National Cancer Institute. Gastric Antral Vascular Ectasia. NCI Thesaurus. Code C84724.

Dilatation of the vessels in the antrum of the stomach. It is associated with portal hypertension, scleroderma, and chronic renal failure. It may cause gastric bleeding. 